\title{
Governança corporativa e estratégia empresarial: mapeamento bibliométrico da produção na área
}

Jonas Lucio Maia

Pós-Doutorado na Fundação Getúlio Vargas FGV-EAESP na área de Financeirização. Doutor em Engenharia de Produção pela Universidade Federal de São Carlos mesma instituição na qual obteve seu grau de mestre e engenheiro. Possui MBA em Finanças pela Fundação Getúlio Vargas/SP, São Paulo, Brasil jonasmaia.dr.eng@outlook.com

Luiz Carlos Di Serio

Professor Titular da Fundação Getulio Vargas - Escola de Administração de Empresas de São Paulo. Graduado em Engenharia Mecânica (UNESP), Título de Mestre na Marquette University (Milwaukee, USA) e de Doutor em Engenharia da Produção na Escola de Engenharia de São Carlos da Universidade de São Paulo.. Coordenador Adjunto do Fórum de Inovação . Membro do Comitê Acadêmico ICCB Instituto Capitalismo Consciente Brasil. Membro do Conselho de Curriculum do Programa MOC/ISC da Harvard, São Paulo, Brasil

luiz.diserio@fgv.br

Editor Científico: José Edson Lara Organização Comitê Científico

Double Blind Review pelo SEER/OJS

Recebido em 14.08.2016

Aprovado em 16.07.2017

Este trabalho foi licenciado com uma Licença Creative Commons - Atribuição - Não Comercial 3.0 Brasil 


\title{
Resumo
}

Dado os profundos impactos da Governança Corporativa na (e a partir da) Estratégia Empresarial, o objetivo deste trabalho é realizar pesquisa bibliométrica sobre a Governança Corporativa e sua relação com a Estratégia, e com isto elaborar um panorama inicial da produção científica na área. Os principais resultados indicam que: (1) uma maior interação entre governança e estratégia parece iniciar-se nos anos 2000, mas muito dos trabalhos referenciam as publicações seminais de teoria da agência; (2) existem vários temas "satélites", como geração de valor ao acionista, instituições, financeirização, etc.; (3) a produção científica parece ser dispersa, pois os 9 principais autores não chegam a totalizar $10 \%$ dos artigos da amostra; (4) Estados Unidos e Inglaterra são os países de maior produção, mas existe grande intercambio entre os países e (5) além dos periódicos típicos, os trabalhos vem sendo publicado em periódicos de economia focados em institucionalismo e de contabilidade e finanças.

Palavras-Chave: Governança Corporativa, Teoria da Agência, Estratégia Empresariais, Financeirização, Pesquisa Bibliométrica.

\section{Corporate governance and business strategy: of bibliometric mapping the scientific production in the field}

\begin{abstract}
Given the impacts of Corporate Governance on (and also emanating from) Business Strategy, the objective of this work is to conduct bibliometric research on Corporate Governance and its relation with the Strategy, and thus produce an initial overview of the scientific production in the field. The main results indicate that: (1) greater interaction between Governance and Strategy has begun in 2000, but much of the work cites seminal publications on agency theory; (2) there are several "peripheral" themes, such as creating value for shareholders, institutions, financialization, etc .; (3) scientific production appears to be dispersed because the 9 main authors sum less than $10 \%$ of the sample items; (4) United States and Britain are the countries with the highest production, but there is great exchange between countries and (5) beyond the typical journals, the work has been published in economics journals focused on institutionalism and accounting and finance journals.
\end{abstract}

Keywords: Corporate Governance, Agency Theory, Business Strategy, Financialization, Bibliometric Research.

\section{Gobierno corporativo y estrategia empresarial: mapeo bibliométrico de la producción en el área}

\section{Resumen}

Dado los profundos impactos de la Gobernanza Corporativa en la (y desde la) Estrategia Empresarial, el objetivo de este trabajo es realizar investigación bibliométrica sobre la Gobernanza Corporativa y su relación con la Estrategia, y con ello elaborar un panorama inicial de la producción científica en el área. Los 
principales resultados indican que: (1) una mayor interacción entre gobierno corporativo y la estrategia parece ser iniciado en la década de 2000, pero gran parte de los trabajos hace referencia a publicaciones seminales de teoría de la agencia; (2) existen varios temas "satélites", como generación de valor al accionista, instituciones, financierización, etc .; (3) la producción científica parece ser dispersa, pues los 9 principales autores no llegan a totalizar el $10 \%$ de los artículos de la muestra; (4) Estados Unidos e Inglaterra son los países de mayor producción, pero hay un gran intercambio entre los países y (5) además de los periódicos típicos, los trabajos se publican en periódicos de economía enfocados en institucionalismo y contabilidad y finanzas.

Palabras clave: Gobierno Corporativo, Teoría de la Agencia, Estrategia Empresarial, Financierización, Investigación Bibliométrica.

\section{Introdução}

Desde o período pós a Segunda Guerra Mundial, o dito "Capitalismo Gerencial" já preconizava a separação entre propriedade e gestão das firmas. Já nos trabalhos iniciais de John Galbraith, a separação entre controle e propriedade das empresas era um fato relevante na nova era do capitalismo, sendo que por conta da assimetria de informação os gestores tinham vantagens e os acionistas tinham apenas um papel passivo na firma - assim, o controle era mais importante que a propriedade (Stockhammer, 2000; Dallery, 2009).

Nas décadas recentes, este dito "Capitalismo Gerencial" tem sido substituído por uma nova forma de Capitalismo supostamente "Dirigido pelas Finanças" (Guttman, 2008). Neste processo, o desalinhamento entre gestores e proprietários (acionistas) precisa ser solucionado por meio de processos e incentivos corretos.

No cerne deste processo de alinhamento está o conceito de Governança Corporativa. Originado dos trabalhos da economia institucional sobre a Teoria da Agência, ele preconiza uma série de princípios e boas práticas que tem atraído grande atenção tanto de gestores quanto dos acadêmicos.

Como a governança corporativa altera de forma impactante aspectos estruturalmente e infra estruturalmente constituintes das próprias organizações, é legítimo assumir que a governança corporativa impacta e tem sido impactada pela própria estratégia das organizações. Assim, o objetivo deste trabalho é realizar uma pesquisa bibliométrica introdutória para explorar o campo de pesquisa da Governança Corporativa e de sua relação com a Estratégia Empresarial, avaliando 
aspectos como principais trabalhos, autores, local de publicação, temas e palavraschave de pesquisa. Busca-se, assim, elaborar um panorama geral da produção científica na área.

Inicialmente são apresentadas rápidas sínteses teóricas sobre os conceitos de Governança Corporativa e de suas raízes na Teoria da Agência. Depois são apresentados os dados da pesquisa bibliométrica propriamente dita, indicando-se as análises de citações e referências, autores e instituições, referências e periódicos, temas e palavras-chave. Por fim, são indicadas as considerações finais e principais conclusões preliminares do trabalho.

\section{Referencial teórico}

De forma muito breve, e apenas para contextualizar a pesquisa bibliométrica que seguirá, as próximas seções buscarão apresentar os temas de Governança Corporativa e sua origem na Teoria da Agência.

A ideia de governança corporativa surge basicamente da dissociação entre a propriedade e a gestão das empresas. Na medida em que ambas são separadas, surge o possível desalinhamento dos interesses entre aquele que efetivamente detém posse legal da firma, e aquele que a gerencia no dia-a-dia. Esta dissociação e desalinhamento de interesses são o grande foco da Teoria da Agência e cujos desdobramentos levam ao conceito de Governança Corporativa aplicado nas empresas. Colocado de forma simples por Froud et al (2006), antes a pergunta era "quem executa o show" (who runs the show), e agora é "como se executa o show" (how the how is run).

\subsection{A teoria da agência}

Nas palavras de Jensen e Meckling (1976, p. 308), "definimos um relacionamento de agência como um contrato no qual uma ou mais pessoas (os principais) engajam outra pessoa (o agente) para desempenhar algum serviço em seu favor, o que envolve delegar alguma autoridade para a tomada de decisão para o agente".

Jensen e Meckling (1976) ainda acrescentam que, se tanto agente quanto principal buscam maximizar seus lucros, existem boas razões para acreditar que o agente não agirá de acordo com os melhores interesses do principal. Dessa forma, 
os principais acabam necessitando desenvolver um arcabouço adicional de incentivos que busque alinhar os interesses dos agentes aos seus, limitando eventuais desvios e garantindo alguma espécie de supervisão. Os custos incorridos para buscar garantir o alinhamento entre principal e agente são referidos de forma geral como custos de agência, e tipicamente incluem: (1) os próprios custos com a criação e estruturação de contratos entre ambas as partes; (2) os custos de monitoramento das atividades dos agentes pelo principal, como relatórios, divulgação de informações, etc; (3) os gastos realizados pelos agentes para promover transparência, mostrando ao principal que suas atitudes não the são prejudiciais e (4) as perdas residuais, decorrentes da diminuição da riqueza (existente ou potencial) dos principais em virtude de decisões do agente que não a buscava maximizar.

Segundo Eisenhardt (1989), a Teoria da Agência busca determinar a forma de contrato que mais eficientemente governe o relacionamento entre principal (o que delega trabalho) e agente (aquele que realiza o trabalho), considerando os pressupostos referentes a pessoas (interesse próprio, racionalidade limitada, aversão a riscos), organizações (conflito de objetivos entre membros) e informação (commoditização das informações). Segundo Eisenhardt (1989), o cerne da teoria da agência é o trade-off entre os custos de medir/monitorar o comportamento e o custo de medir os resultados e transferir o risco para o agente.

Para Perrow (1986) três premissas são centrais à teoria da agência. A primeira é comum à maioria dos economistas: os indivíduos maximizam seu interesse próprio. A segunda é mais específica a esta teoria: a vida social é um conjunto de contratos, ou trocas, governados pelo interesse próprio competitivo. A terceira se aplica a analise interna das organizações: monitorar os contratos é custoso e de certa forma ineficaz, especialmente em organizações, encorajando o comportamento do interesse próprio, esquiva do trabalho, e especialmente o oportunismo pela fraude. Os contratos serão violados devido ao interesse próprio, e podem ser violados devido aos custos e ineficácia da fiscalização.

Para os seguidores da teoria da agência, mesmo se as ocorrências sejam não planejadas, sem fraude, e meramente devido ao deslize que ocorre na vida social: esquecimento, sorte, etc. o indivíduo racional levará isso para seu interesse próprio sempre que possível. Além disso, os humanos são altamente adaptativos (também inventivos, variáveis, etc.). Desta forma, o cenário nos quais as interações 
ou contratos ocorrem são a coisa mais importante a se considerar quando se explica o comportamento. Perrow (1986) segue Hobert Simon e assume que a racionalidade é limitada, então, mesmo onde o interesse próprio é encorajado pelo contexto do comportamento, os humanos (1) não têm proveitos claros para maximizar, (2) não tem muita da informação necessária para maximizar os proveitos e (2) não conhecem as relações causa-efeito da maximização do comportamento. Os teóricos da agência não modelam o contexto do comportamento, nem o deslize ocasionado pela racionalidade limitada, mesmo que ambos estes fatores sejam responsáveis pela maioria da variação observada. Outro problema, a teoria da agência parece ser ideologicamente incapaz de olhar ambos os lados de um contrato, e incapaz de notar qualquer assimetria permanente dos recursos ou poder que emane do contexto.

Então, por que se ocupar com esta teoria? Primeiro, porque juntamente com a economia de custos de transação, está experimentando grande crescimento de popularidade junto aos teóricos organizacionais. Segundo, ela destaca o grau variável no qual a maioria das teorias organizacionais reconhece a assimetria de poder nas organizações. Mas a melhor razão para prestar atenção na teoria da agência é que ela nos força a considerar condições sob as quais as organizações podem promover o comportamento de interesse próprio, e quando eles podem promover o comportamento pelo interesse dos outros:

- $\quad$ Comportamento de interesse próprio é favorecido quando interações continuadas são minimizadas;

- $\quad$ Comportamento de interesse próprio é favorecido quando o acumulo de recompensas e excesso pelos indivíduos é encorajado;

- $\quad$ Comportamento de interesse próprio é favorecido quando o esforço ou contribuição individual é encorajado;

- Comportamento de interesse próprio é favorecido quando nos minimizamos o esforço interdependente através do fluxo de trabalho e equipamento;

- Comportamento de interesse próprio e favorecido quando há preferência pela estabilidade de liderança e autoridade generalizada;

- Comportamento de interesse próprio é favorecido quando altas hierarquias são favorecidas. 


\subsection{Governança Corporativa}

Se os conflitos da teoria da agência existem, alguma área da administração necessita definir formas de lidar com os mesmos - e isto é feito pelos estudos em Governança Corporativa. De acordo com Shleifer e Vishny (1997), a governança corporativa lida com as formas pelas quais os fornecedores de recursos financeiros para as firmas garantem que terão os devidos retornos de seus investimentos.

Diversas definições sobre o conceito de governança corporativa existem, e uma revisão destes está fora do escopo deste trabalho. Contudo, duas serão trazidas aqui para ilustrar o conceito: para Rajan e Zingales (1997, p. 4), a governança corporativa pode ser definida como "um conjunto complexo de restrições que dão forma à barganha ex-post sobre as quase-rendas geradas pela firma"; já para Shleifer e Vishny (1997, p. 743), muito da governança corporativa lida com "as restrições que os gestores colocam sobre si próprios, ou que os investidores colocam sobre os gestores, de forma a reduzir a má alocação ex-post de recursos e assim induzir os investidores a prover mais recursos financeiros ex-ante".

Devido à grande profusão de conceitos e definições, se consideram aqui mais relevantes os grandes temas centrais que a governança busca tratar por meio de princípios de boas práticas, modelos de gestão e mecanismos de regulação (Donadone et al, 2009).

Andrade e Rosseti (2004), citado por Donadone et al (2009), apresentam os seguintes princípios como centrais para a governança: (1) equidade ( fairness), que se refere a justiça no tratamento dos acionistas, principalmente respeitando acionistas minoritários; (2) transparência de informações (disclosure) de forma a dar visibilidade sobretudo àquelas de alta relevância que podem implicar alterações ou riscos para os negócios e seus resultados financeiros; (3) prestação de contas (accountability), por meio dos melhores princípios e práticas contábeis e de auditoria e (4) conformidade (compliance) no cumprimento de leis e normas, estabelecidas nas mais diversas esferas.

Jensen (1993) apresenta quatro distintos grupos de forças de controle agindo sobre as organizações com o objetivo de resolver a divergência entre as decisões dos gestores e aquelas que seriam ótimas para a sociedade. Os ditos "mecanismos" 
da governança corporativa podem ser categorizados dentro destes quatro grupos distintos, a saber:

- Os mercados de capitais;

- O sistema legal, político e regulatório;

- Os mercados de produtos e fatores de produção e;

- Os mecanismos internos de controle;

Os mecanismos internos de controle, por sua vez, serão aqui analisados em maior nível de detalhe.

Os conselhos de administração, conforme coloca Gillan (2006), são o ponto essencial de implementação da governança corporativa. Com obrigações inclusive legais para com os acionistas, os conselhos devem prover orientação estratégica e monitoramento. Conforme define o IBGC (2004, p. 29), " o Conselho de Administração, órgão colegiado encarregado do processo de decisão de uma organização em relação ao seu direcionamento estratégico, é o principal componente do sistema de governança. Seu papel é ser o elo entre a propriedade e a gestão para orientar e supervisionar a relação desta última com as demais partes interessadas. O Conselho recebe poderes dos sócios e presta contas a eles."

As políticas de remuneração definem os montantes e formas de incentivos financeiros que serão concedidos aos executivos e conselheiros por meio de sua remuneração. Segundo Okimura (2003), dois aspectos são relevantes nesse contexto: o nível de remuneração e como esta tem seu papel atrelado ao desempenho da empresa.

De alguma forma, duas premissas estão por trás do uso das políticas de remuneração como mecanismo de governança. Primeiro, que o administrador tende a arriscar menos seu emprego quanto maior for a remuneração proveniente dele - $e$ arriscar menos o emprego aqui significa agir de acordo com o interesse dos acionistas (Jensen e Ruback (1983) definem como "controle corporativo" o direito dos acionistas de contratar, demitir e definir a remuneração dos gestores). Segundo, atrelar remuneração à desempenho da empresa gera maiores incentivos para que os administradores busquem maximizar a riqueza do acionista se, com esta conduta, forem recompensados de forma proporcional (Okimura, 2003).

A estrutura de propriedade pode apresentar maior grau de concentração ou de dispersão, gerando níveis variados de riscos, benefícios e custos aos acionistas 
minoritários. Para Denis (2001), em geral acionistas com mais de 5\% das ações da empresa são significantes suficiente para terem o incentivo e o poder de monitorar a administração da companhia. De acordo com o IBGC (2004, p. 21), cada sócio é essencialmente um proprietário da organização, de forma que o poder político (representado pelo direito ao voto) deve estar equilibrado com o poder econômico. A vinculação proporcional entre direito de voto e participação no capital favorece o alinhamento de interesses entre os sócios.

A estrutura de capital ou de financiamento versa basicamente sobre a decisão entre financiamento das atividades por meio de capital próprio ou de dívidas. Os trabalhos de Jensen (1986) e Hart (1995) sugerem que uma estrutura de financiamento com maior participação de dívidas pode agir como um instrumento disciplinador dos gestores, na medida em que a necessidade de quitação das mesmas criaria a necessidade de comprometimento em um nível mínimo de desempenho e impediria que os gestores utilizassem os fluxos de caixa livre a seu bel prazer (dado que as dívidas obrigatoriamente precisam ser pagas).

De acordo com Stockhammer (2003), o crescimento da governança corporativa é um processo fundamentalmente de alteração de poder e, por isso, é esperado que alguns advoguem a favor e outros contra. Aqueles que defendem o conceito, inerentemente se apegam aos seus valores de transparência e de equidade. Por outro lado, Erturk et al (2008) critica a proposta da governança, afirmando que esta é uma prática "impossibilista", na medida em que infla as expectativas mas estabelece objetivos fundamentalmente não atingíveis propagandeando o que os autores chamam de "mentiras sinceras" que no longo tempo invariavelmente geram descrédito.

Outra crítica, trazida por Capron (2005) é de que a governança corporativa, por utilizar a contabilidade como linguagem e sistema de comunicação das informações financeiras, também traz impactos para as normas contábeis internacionais. As informações têm sido focalizadas nas necessidades dos investidores, e cada vez menos para os governos, assalariados, etc. - gerando cada vez mais a necessidade de informações adicionais. Como essas novas normas são propostas por organismos internacionais, tem-se certa falta de controle "político e social" destas, privilegiando as necessidades dos investidores em detrimento das necessidades de outros grupos interessados. 


\subsection{Método e Plano de Pesquisa}

Conforme previamente mencionado, será empregada a análise bibliométrica para atingir o objetivo planejado para este trabalho. Figueiredo (1973, p. 127) define a Bibliometria como "a análise estatística dos processos de comunicação escrita, tratamento quantitativo (matemático e estatístico) das propriedades e do comportamento da informação registrada". Assim, seus principais objetivos são esclarecer os processos de comunicação e evolução de uma disciplina por meio da quantificação e análise de suas diversas facetas, reunindo e interpretando dados estatísticos relativos aos veículos de comunicação (livros, periódicos, etc.) para demonstrar evolução e utilização histórica (Maia, 1973)

A bibliometria se embasa em pelo menos três distintas leis sobre a distribuição bibliométrica. Embora não seja objetivo aqui aprofundar em tais leis, sucintamente pode-se colocar (Vanti, 2002 e Guedes e Borschiver, 2005): (1) a Lei de Lotka, que almeja medir a produtividade dos autores, identificar centros de pesquisa desenvolvidos em determinada área e reconhecer a solidez de um determinado campo científico; (2) a Lei de Zipf, que mede a frequência de determinadas palavras nos textos, produzindo assim uma lista de termos dentro de uma disciplina, conforme sua relevância - dessa forma, a concentração de palavras com alto conteúdo semântico poderia ser usada como forma de indexação do texto devido a sua representatividade dentro da temática; (3) a Lei de Bradford, que mede a produtividade dos periódicos estimando sua relevância dentro de uma determinada área do conhecimento - periódicos com maior número de artigos acerca de um determinado tema formam, supostamente, um conjunto de veículos com maior relevância para certa área.

Utilizando as leis acima apresentadas, foi definida uma sequência de etapas para a execução da análise bibliométrica deste trabalho. A primeira etapa se refere à consulta propriamente dita, executada dentro de uma base de indexação de trabalhos. A segunda compreende a aplicação dos devidos filtros, de palavras de busca, tipos de publicação, lapso de tempo, etc., para correta delimitação da amostra de trabalhos a ser estudada. A terceira etapa contempla a análise descritiva e temporal dos artigos obtidos na amostra, contextualizando a produção científica (publicações e citações) no tempo e identificando os principais trabalhos na área. A quarta etapa se embasa na Lei de Lotka para identificar os autores, instituições e 
países mais relevantes, utilizando rankings e mapas de cocitação. A etapa seguinte analisa aonde o tema vem sendo publicado, baseando-se na Lei de Bradford, para identificar os principais periódicos, áreas de pesquisa, etc. A sexta etapa utiliza a Lei de Zipf para analisar as principais palavras-chave na indexação dos trabalhos da amostra, bem como os principais termos que podem ser identificados nos artigos, retratando quais conceitos são trabalhados conjuntamente e como estes se relacionam. Por fim, os resultados de todas estas etapas são conjuntamente analisados e são produzidas as principais conclusões sobre a pesquisa.

\subsection{Pesquisa Bibliométrica}

Os dados utilizados na análise bibliométrica deste artigo foram os documentos encontrados na base de dados Web of Science, os quais são publicados pela Thomson Reuters. O processo de busca de documentos foi executado tendo como base nas seguintes palavras-chave: "corporate governance" AND "strategy". A partir deste resultado, os documentos foram refinados em critérios de busca de acordo com a Tabela 1.

\section{TABELA 1}

Filtros com critérios de busca

\begin{tabular}{|c|c|}
\hline Tipo & $\begin{array}{l}\text { Artigos, revisões, capítulos de livros ou trabalhos de } \\
\text { congresso. }\end{array}$ \\
\hline $\begin{array}{c}\text { Áreas } \\
\text { conhecimento }\end{array}$ & $\begin{array}{c}\text { Management OR Business OR Business Finance OR } \\
\text { Economics OR Operations Research Management Science OR } \\
\text { Psychology Applied OR Humanities Multidisciplinary OR Planning } \\
\text { Development OR Engineering Industrial OR Social Sciences } \\
\text { Interdisciplinary OR Social Sciences Mathematical Methods OR } \\
\text { Information Science Library Science OR Social Issues OR History } \\
\text { Of Social Sciences OR Engineering Multidisciplinary }\end{array}$ \\
\hline Tempo & \multicolumn{2}{|c|}{ Sem restrições } \\
\hline
\end{tabular}

Fonte: Elaborado pelos autores.

Desta busca e refino, foram obtidas 496 publicações. Para a análise dos dados dos documentos encontrados, foram utilizadas planilhas eletrônicas e o software VOSViewer (Van Eck e Waltman, 2010), 


\subsubsection{Análise descritiva de citações e referências}

A figura 2 ilustra o ano de publicação dos artigos, para dar indicativo da produção de conhecimento ao longo do tempo. Como pode ser observado, o número de publicações tem aumentado ao longo dos últimos anos, principalmente de 2007 para frente, pois este período concentra $77 \%$ do total de publicações, com uma média de 47,2 publicações por ano. Contudo, esta afirmação deve ser colocada em perspectiva, pois conforme afirma Neely(2005), a base Web of Science possui mais informações sobre publicações mais recentes e recentemente existe uma tendência de aumento na quantidade de publicações acadêmicas.

\section{FIGURA 2}

Número de publicações por ano.

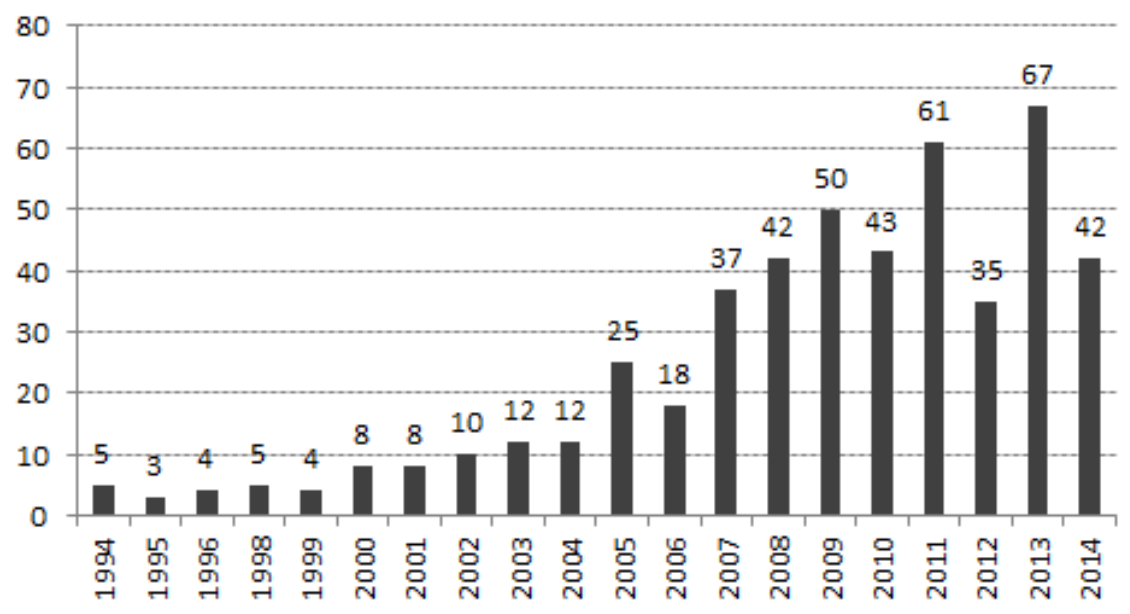

Fonte: Elaborado pelos autores.

De forma complementar, a Figura 3 ilustra a quantidade de citações para os artigos da pesquisa ao longo de cada um dos anos. Da observação pode-se identificar que a maior parte das citações ocorre no período iniciado em 2003, totalizando $96 \%$ do total de citações e com uma média de 907 citações por ano. Similarmente às próprias publicações, existe uma maior tendência dos artigos da pesquisa serem referenciados nos últimos anos. 
Figura 3

Número de citações aos artigos da amostra por ano.

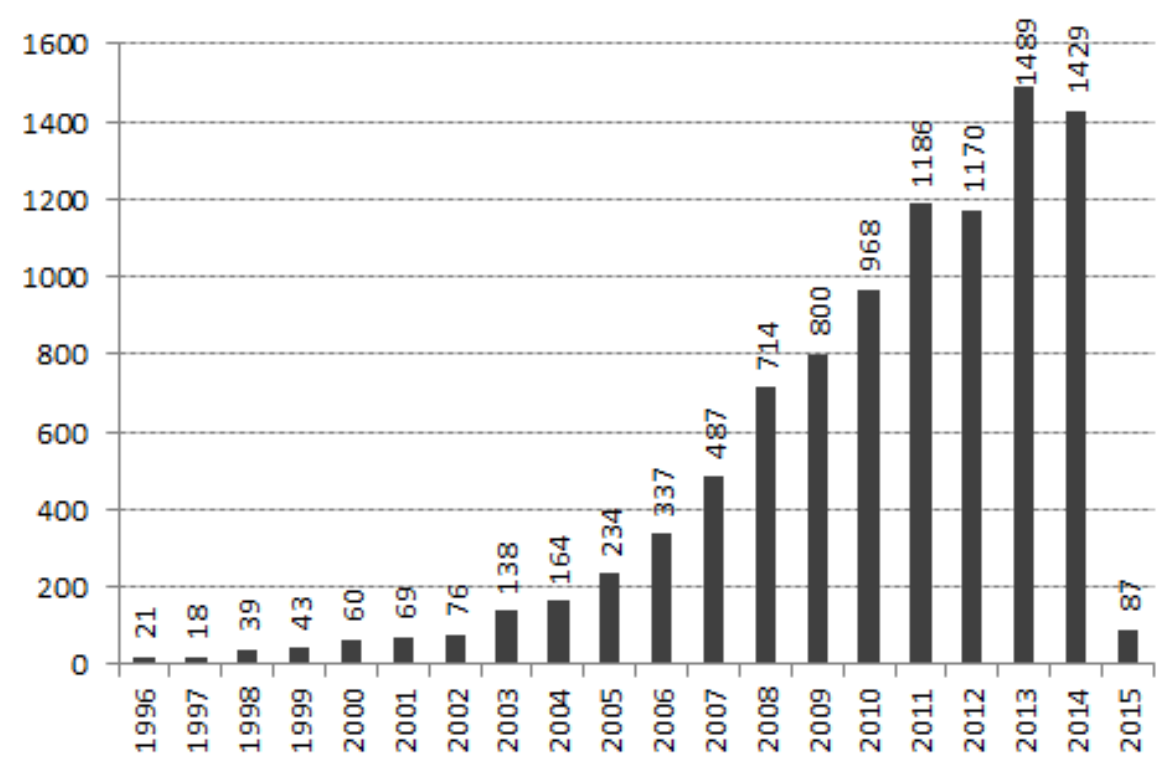

Fonte: Elaborado pelos autores.

Buscando trazer maior detalhamento, a tabela 4 apresenta as publicações que apresentam maior número de citação aos artigos da amostra. Aparentemente, os principais artigos se agrupam ao longo de quatro temas: (1) aquele focalizados na própria governança corporativa, como 1, 5, 6 e 7, (2) aqueles que tratam da estratégia e de suas particularidades, como 2 e 9, (3) um especificamente em um tema que une governança e estratégia por meio da geração de valor ao acionista, o artigo 4 e (4) uma série de artigos tratando de temas correlatos como venture capital, instituições, etc., como 3, 8 e 10. 
Governança corporativa e estratégia empresarial: mapeamento bibliométrico da produção na área

TABELA 4 - Publicações com maior número de citação à amostra

\begin{tabular}{|c|c|c|c|c|}
\hline \# & $\begin{array}{l}\text { Nro } \\
\text { Citaçõ }\end{array}$ & & & \\
\hline & es & Autores & Título & Publicação \\
\hline 1 & 989 & $\begin{array}{l}\text { Gompers, P; Ishii, } \\
\text { J; Metrick, A }\end{array}$ & $\begin{array}{l}\text { Corporate governance and equity } \\
\text { prices }\end{array}$ & $\begin{array}{l}\text { QUARTERLY JOURNAL OF } \\
\text { ECONOMICS Volume: } 118 \\
\text { Issue: } 1 \text { Pages: } 107-155\end{array}$ \\
\hline 2 & 735 & $\begin{array}{l}\text { Hoskisson, RE; } \\
\text { Eden, L; Lau, CM; } \\
\text { Wright, M }\end{array}$ & Strategy in emerging economies & $\begin{array}{l}\text { ACADEMY OF } \\
\text { MANAGEMENT JOURNAL } \\
\text { Volume: } 43 \text { Issue: } 3 \\
\text { Pages: } 249-267\end{array}$ \\
\hline 3 & 306 & $\begin{array}{l}\text { Black, BS; Gilson, } \\
\text { RJ }\end{array}$ & $\begin{array}{l}\text { Venture capital and the structure } \\
\text { of capital markets: banks versus } \\
\text { stock markets }\end{array}$ & $\begin{array}{l}\text { JOURNAL OF FINANCIAL } \\
\text { ECONOMICS Volume: } 47 \\
\text { Issue: } 3 \text { Pages:243-277 }\end{array}$ \\
\hline 4 & 283 & $\begin{array}{l}\text { Lazonick, W; } \\
\text { O'Sullivan, M }\end{array}$ & $\begin{array}{l}\text { Maximizing shareholder value: a } \\
\text { new ideology for corporate } \\
\text { governance }\end{array}$ & $\begin{array}{l}\text { ECONOMY AND SOCIETY } \\
\text { Volume: } 29 \text { Issue: } 1 \\
\text { Pages:13-35 }\end{array}$ \\
\hline 5 & 250 & Zahra, SA & $\begin{array}{l}\text { Governance, ownership, and } \\
\text { corporate entrepreneurship: The } \\
\text { moderating impact of industry } \\
\text { technological opportunities }\end{array}$ & $\begin{array}{l}\text { ACADEMY OF } \\
\text { MANAGEMENT JOURNAL } \\
\text { Volume: } 39 \text { Issue: } 6 \\
\text { Pages: } 1713-1735\end{array}$ \\
\hline 6 & 220 & $\begin{array}{l}\text { Johnson, RA; } \\
\text { Greening, DW }\end{array}$ & $\begin{array}{l}\text { The effects of corporate } \\
\text { governance and institutional } \\
\text { ownership types on corporate } \\
\text { social performance }\end{array}$ & $\begin{array}{l}\text { ACADEMY OF } \\
\text { MANAGEMENT JOURNAL } \\
\text { Volume: } 42 \text { Issue: } 5 \\
\text { Pages:564-576 }\end{array}$ \\
\hline 7 & 190 & $\begin{array}{l}\text { Young, Michael N.; } \\
\text { Peng, Mike W.; } \\
\text { Ahlstrom, David; } \\
\text { Bruton, Garry D.; } \\
\text { Jiang, Yi }\end{array}$ & $\begin{array}{l}\text { Corporate governance in } \\
\text { emerging economies: A review of } \\
\text { the principal-principal perspective }\end{array}$ & $\begin{array}{l}\text { JOURNAL OF } \\
\text { MANAGEMENT STUDIES } \\
\text { Volume: } 45 \text { Issue: } 1 \\
\text { Pages: } 196-220\end{array}$ \\
\hline 8 & 188 & $\begin{array}{l}\text { Meyer, Klaus E.; } \\
\text { Estrin, Saul; } \\
\text { Bhaumik, Sumon } \\
\text { Kumar; Peng, Mike } \\
\text { W. }\end{array}$ & $\begin{array}{l}\text { INSTITUTIONS, RESOURCES, } \\
\text { AND ENTRY STRATEGIES IN } \\
\text { EMERGING ECONOMIES }\end{array}$ & $\begin{array}{l}\text { STRATEGIC } \\
\text { MANAGEMENT JOURNAL } \\
\text { Volume: } 30 \text { Issue: } 1 \\
\text { Pages: } 61-80\end{array}$ \\
\hline 9 & 185 & $\begin{array}{l}\text { Carpenter, MA; } \\
\text { Westphal, JD }\end{array}$ & $\begin{array}{l}\text { The strategic context of external } \\
\text { network ties: Examining the } \\
\text { impact of director appointments } \\
\text { on board involvement in strategic } \\
\text { decision making }\end{array}$ & $\begin{array}{l}\text { ACADEMY OF } \\
\text { MANAGEMENT JOURNAL } \\
\text { Volume: } 44 \text { Issue: } 4 \\
\text { Pages: } 639-660\end{array}$ \\
\hline 10 & 177 & $\begin{array}{l}\text { Meyer, KE; Peng, } \\
\text { MW }\end{array}$ & $\begin{array}{l}\text { Probing theoretically into Central } \\
\text { and Eastern Europe: } \\
\text { transactions, resources, and } \\
\text { institutions }\end{array}$ & $\begin{array}{l}\text { JOURNAL OF } \\
\text { INTERNATIONAL } \\
\text { BUSINESS STUDIES } \\
\text { Volume: } 36 \text { Issue: } 6 \\
\text { Pages:600-621 }\end{array}$ \\
\hline
\end{tabular}

Fonte. Elaborada pelos autores

Ao analisar os principais periódicos nos quais os artigos desta pesquisa são citados, tem-se que estes geralmente estão centrados em periódicos sobre Gestão (Journal of Management Studies, Academy of Management Journal), sobre Economia (Quarterly Journal of Economics, Economy and Society) e sobre 
Estratégia (Strategic Management Journal).

\subsubsection{Análise descritiva de autores e instituições}

A tabela 5 ilustra os principais autores dos trabalhos obtidos via a pesquisa bibliométrica. Pôde ser identificada alguma dispersão acerca da produção científica do tema, dado que nove autores são responsáveis por pouco mais de $10 \%$ das publicações. James Westphal, da Universidade de Michigan nos Estados Unidos é o autor mais profícuo.

TABELA 5

Autores mais profícuos

\begin{tabular}{lrr} 
Autores & $\begin{array}{c}\text { Nro } \\
\text { Trabalhos }\end{array}$ & \\
Westphal Jd & 9 & $2 \%$ \\
\hline Peng Mw & 7 & $1 \%$ \\
\hline Hoskisson Re & 7 & $1 \%$ \\
\hline Toms S & 7 & $1 \%$ \\
\hline Miller D & 7 & $1 \%$ \\
\hline Le Breton-Miller I & 6 & $1 \%$ \\
\hline Zajac Ej & 5 & $1 \%$ \\
\hline Yoshikawa T & 5 & $1 \%$ \\
\hline Van Oosterhout J & 4 & $1 \%$ \\
\hline Outros & 439 & $89 \%$ \\
\hline Fonte: Elaborado pelos autores. & &
\end{tabular}

O software VOSViewer foi empregado para construir um diagrama das cocitações de autores, isto é, autores cujos trabalhos tipicamente são referenciados conjuntamente dentro dos artigos da área. 


\section{Figura 6}

Diagrama de cocitação de autores (mínimo 53 citações)

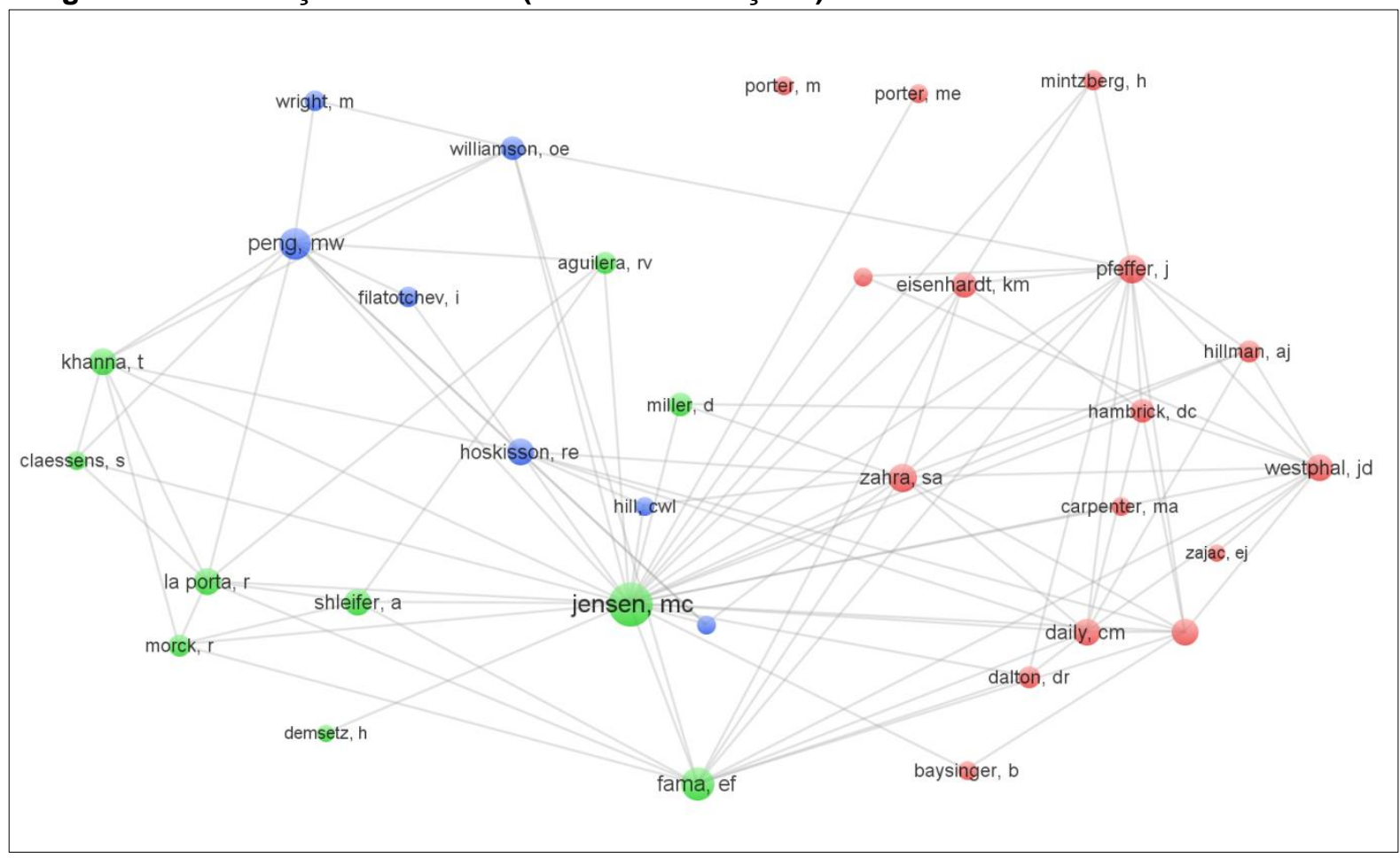

Fonte: Elaborado pelos autores.

A figura 6 mostra esta rede de cocitação, que gerou 3 clusters distintos (cores verde, vermelho e roxo). Primeira observação, nesta análise o economista Michael Jensen ganha maior relevância, se transformando em um nodo central - isso em alguma medida pode denotar que seus trabalhos em Custos de Agência e Teoria da Firma são "embrionários" para os desenvolvimentos dos outros autores. O cluster vermelho parece reunir pesquisadores mais enfocados em estratégia, como é o caso de Michael Porter e Henry Mintzberg. O cluster verde parece centralizar-se em pesquisadores que lidam principalmente com custos da agência, como Eugene Fama e Rafael La Porta. Por fim, o cluster roxo traz autores típicos de governança como Oliver Williamson e Michael Peng.

Derivada da análise dos pesquisadores, as tabelas 7 e 8 apresentam as universidades cujos autores mais publicaram no tema, e o respectivo país no qual são sediadas. Os Estados Unidos e a Inglaterra são os países que parecem se diferenciar na publicação sobre este tema. No primeiro, estão as universidades de Harvard, Texas (Dallas, Austin) e Pennsylvania, enquanto que no segundo estão as universidades de Nottingham, London e City London. A única exceção que apareceu 
entre as principais universidades é a Erasmus, na Holanda.

\begin{tabular}{|c|c|c|}
\hline Organização & Nro Trabalhos & $\%$ \\
\hline Harvard University & 14 & $3 \%$ \\
\hline University Of Nottingham & 13 & $3 \%$ \\
\hline University Of Texas Dallas & 11 & $2 \%$ \\
\hline University Of London & 10 & $2 \%$ \\
\hline Texas A M University System & 9 & $2 \%$ \\
\hline Texas A M University College Station & 9 & $2 \%$ \\
\hline Erasmus University Rotterdam & 9 & $2 \%$ \\
\hline $\begin{array}{c}\text { Pennsylvania Commonwealth System } \\
\text { Of Higher Education Pcshe }\end{array}$ & 8 & $2 \%$ \\
\hline City University London & 8 & $2 \%$ \\
\hline Outros & 405 & $82 \%$ \\
\hline
\end{tabular}

Tabela 8

Países mais profícuos

\begin{tabular}{|c|c|c|}
\hline $\mathrm{Pa}$ & Nro Trabalhos & $\%$ \\
\hline Estados Unidos & 161 & $32 \%$ \\
\hline Inglaterra & 78 & $16 \%$ \\
\hline China & 60 & $12 \%$ \\
\hline Australia & 38 & $8 \%$ \\
\hline Canada & 33 & $7 \%$ \\
\hline Espanha & 25 & $5 \%$ \\
\hline Taiwan & 23 & $5 \%$ \\
\hline Holanda & 22 & $4 \%$ \\
\hline Outros & 56 & $11 \%$ \\
\hline
\end{tabular}

Fonte: Elaborado pelos autores.

A figura 9 apresenta um diagrama de agrupamento das universidades, conectando-as conforme as afiliações dos autores e dos artigos que eles citam em seus trabalhos. O software VOSViewer produziu cinco clusters diferentes, e o que se destaca é que aparentemente os todos os clusters congregam universidades de diferentes países, não existindo assim uma "regionalização" na pesquisa: o verde possui universidades americanas e holandesas, o azul com americanas e inglesas, o vermelho com holandesas, australianas, etc; o roxo com canadenses e americanas. Apenas o cluster amarelo manteve apenas universidades americanas. 


\section{Figura 9}

Diagrama agrupamento das universidades (mínimo 6 ocorrências)

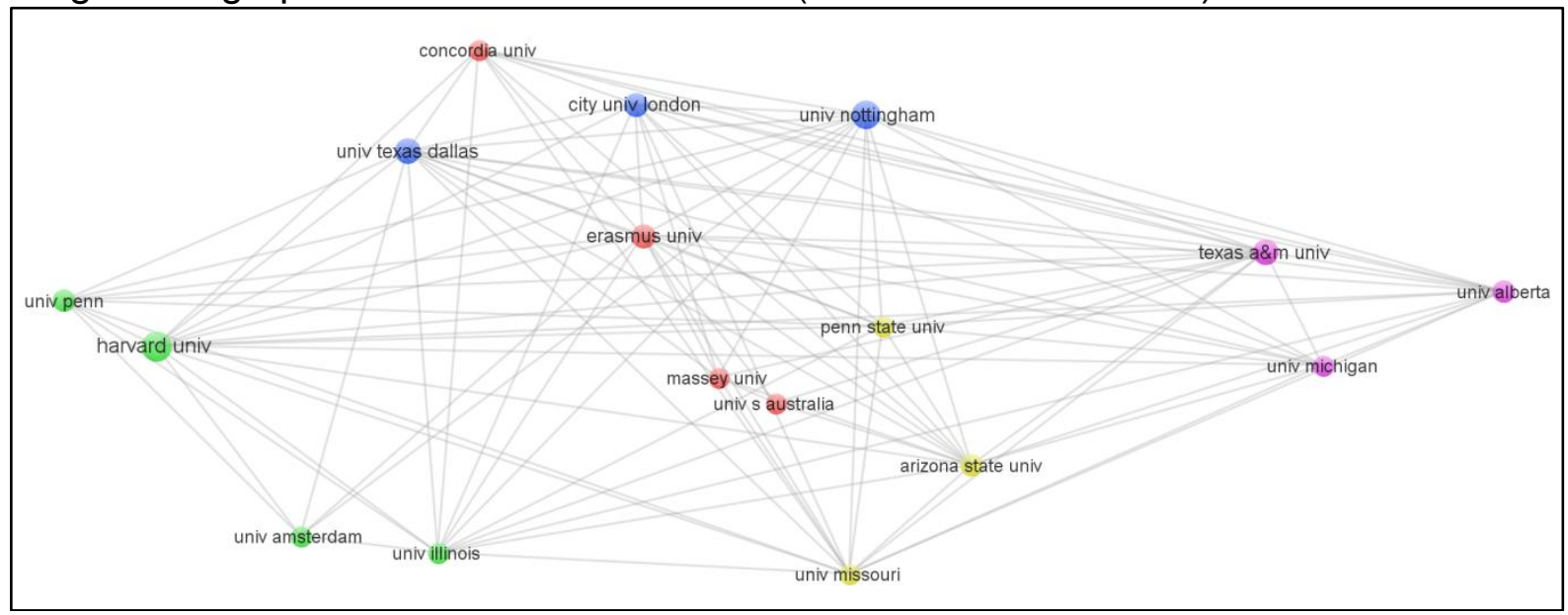

Fonte: Elaborado pelos autores.

\subsubsection{Análise das referências, periódicos e áreas}

A figura 10 mostra a análise de cocitações das referências trazidas na pesquisa bibliométrica. Esta análise busca identificar a quantidade de vezes que dois trabalhos são citados simultaneamente em um mesmo artigo, denotando proximidade temática entre autores e redes de pesquisa.

De forma a se extrair maior significado dos resultados, foi estabelecido como 24 o número mínimo de referências aos artigos. Foram produzidos três clusters distintos; (1) o Vermelho, centralizados em vários trabalhos de Jensen e Fama com trabalhos centrais à Teoria da Agência e Governança; (2) o Roxo, com trabalhos de Dimaggio, North e La Porta sobre aspectos da Nova Economia Institucional, e (3) Verde com trabalhos mais voltados para a estratégia, desempenho e governança, como os de Pettigrew, Hillman entre outros.

A tabela 11 apresenta os periódicos nos quais os artigos mais referenciados pelos trabalhos da pesquisa foram publicados. Os canais de publicação aparentemente são também dispersos, dado que os 10 principais periódicos reúnem pouco mais de $25 \%$ dos trabalhos da amostra. Dentre os jornais, podem-se identificar aqueles vinculados a Governança Corporativa (Corporate Governance, Governance), a Ética nos Negócios (Journal of Business Ethics), a Estratégia (Strategic Management Journal) e a Gestão (Journal of Management Studies, 
Academy of Management, Management Decision).

\section{Figura 10}

Diagrama de Cocitações (mínimo 24 referências)

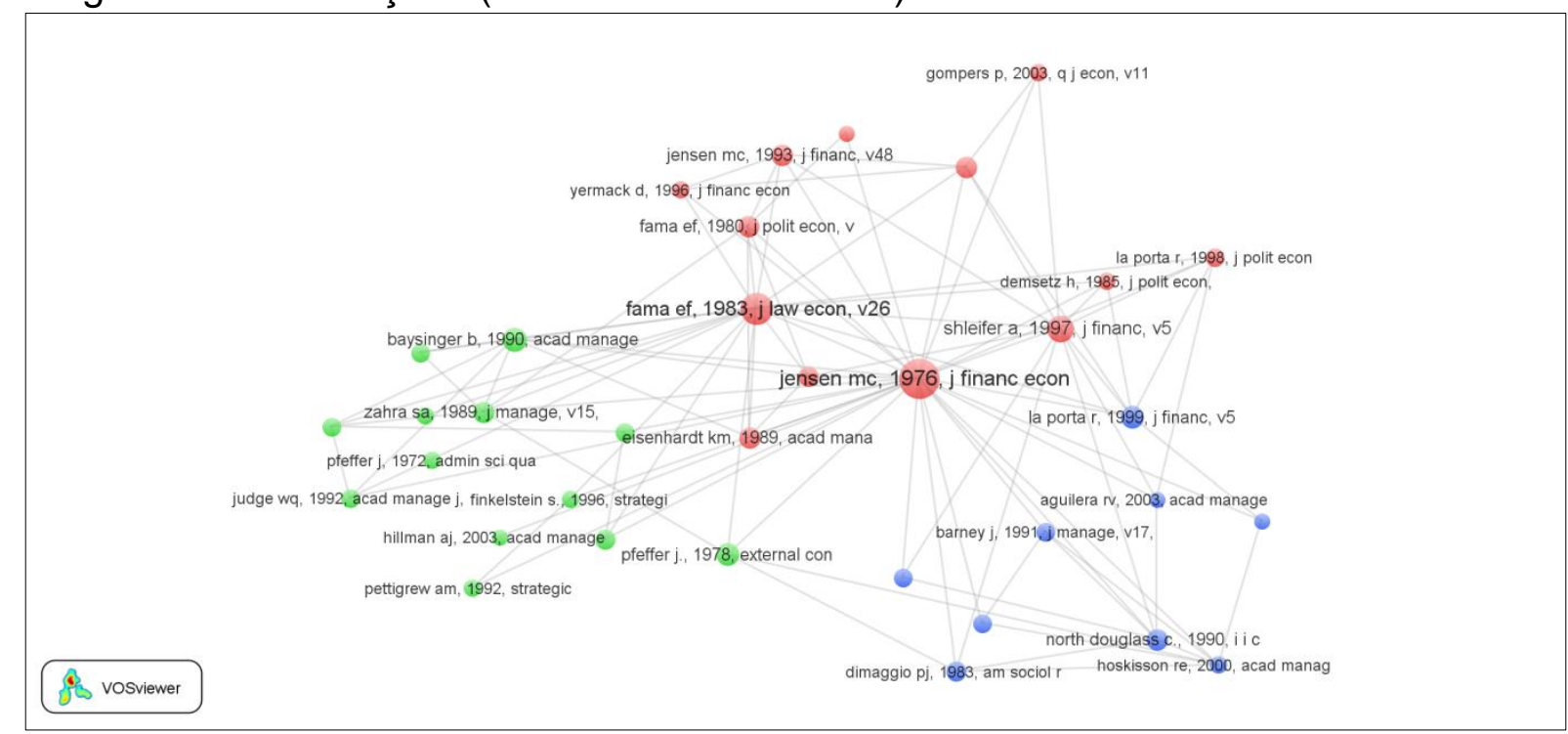

Fonte: Elaborado pelos autores.

$\begin{aligned} & \text { Tabela } \mathbf{1 1} \\
& \text { Periódicos mais citados } \\
& \text { Jornais }\end{aligned}$
\begin{tabular}{ccc} 
Corporate Governance-An International Review & 32 & $6 \%$ \\
\hline Journal Of Business Ethics & 23 & $5 \%$ \\
\hline Strategic Management Journal & 20 & $4 \%$ \\
\hline Journal Of Management Studies & 11 & $2 \%$ \\
\hline Academy Of Management Journal & 9 & $2 \%$ \\
\hline Asia Pacific Journal Of Management & 9 & $2 \%$ \\
\hline Management Decision & 8 & $2 \%$ \\
\hline Journal Of International Business Studies & 8 & $2 \%$ \\
\hline Governance & 8 & $2 \%$ \\
\hline Journal Of Business Research & 7 & $1 \%$ \\
\hline Outros & 361 & $73 \%$ \\
\hline
\end{tabular}

Fonte: Elaborado pelos autores.

Foi construído, na figura 12, um diagrama de cocitação dos periódicos, ilustrando quais periódicos são tipicamente referenciados juntos. Três clusters foram obtidos: (1) o Roxo, que mostra uma interessante interação entre periódicos de Governança Corporativa e de Estratégia (Strategic Management, Harvard Business Review); (2) o Vermelho com os periódicos típicos de gestão (Academy of Management, Strategic Management, Journal of Business Studies) (3) o Verde, claramente com periódicos mais voltados para finanças e contabilidade. 


\section{Figura 12}

Diagrama de cocitação de periódicos

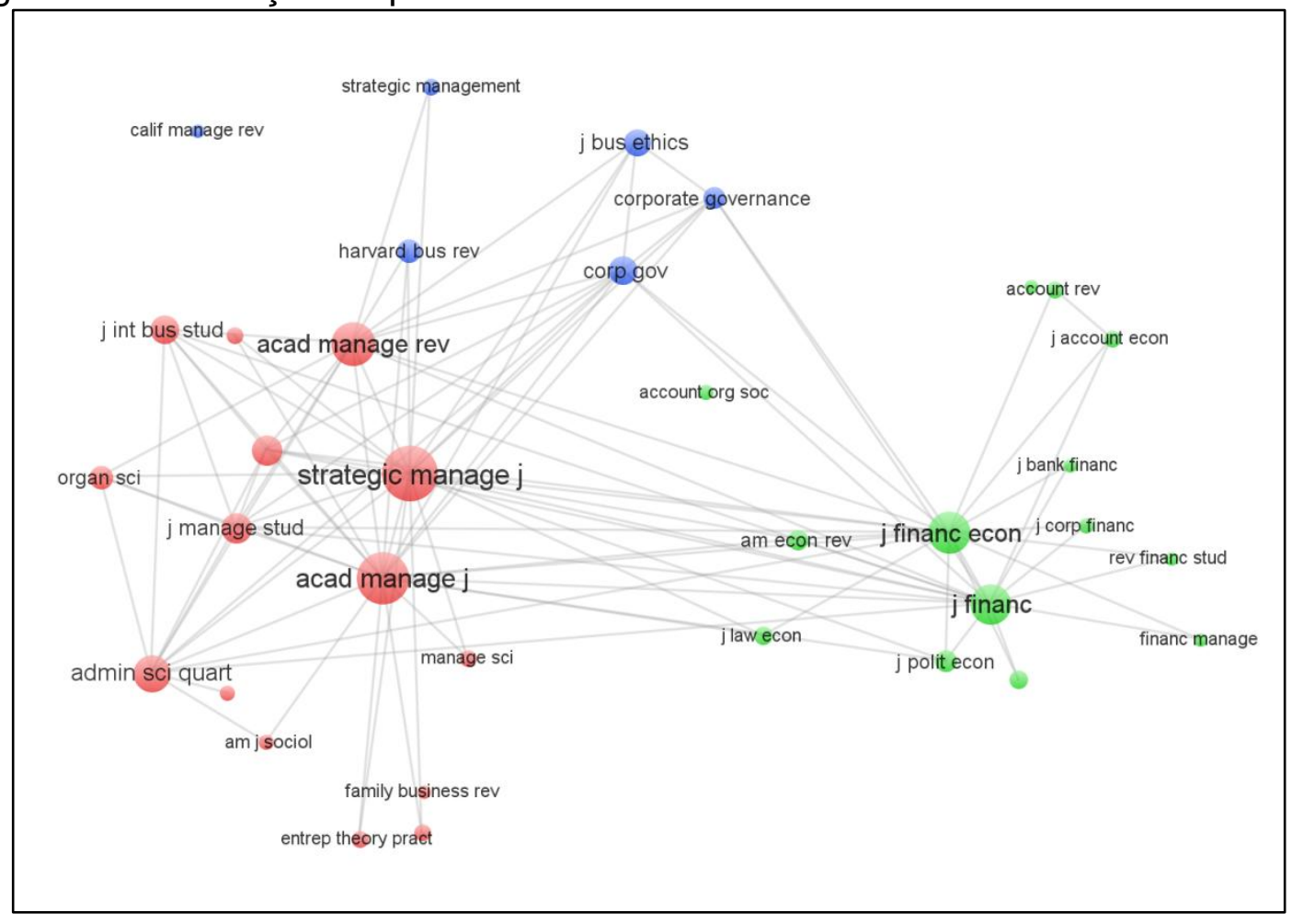

Fonte: Elaborado pelos autores.

\subsection{Análises de Termos e Palavras-Chave}

A figura 13 traz a frequência das palavras-chave nos artigos obtidos por meio desta pesquisa bibliométrica. Como seria de se esperar, inclusive pelos próprios filtros executados na pesquisa, Governança Corporativa, Governança e Estratégia são as principais palavras chave. As diversas outras palavras parece sem derivadas ou relacionadas também aos conceitos de governança corporativa (teoria da agência, estrutura de propriedade, board de diretores, remuneração executiva) ou de estratégia (desempenho, estratégia corporativa, diversificação). Vale também o destaque para a responsabilidade social corporativa, que aparece com algum destaque provavelmente por sua própria relação com a ética nos negócios.

Utilizando a função de identificação de termos do VOSViewer, que busca termos tanto no título quanto no resumo dos artigos, foi construído o diagrama de relacionamento de termos da figura 14. Estratégia e governança corporativa obviamente também são as principais ocorrências, e dois clusters distintos foram 
produzidos: um verde cujos principais nodos parecem estar centrados em temas como desempenho das firmas, e outro vermelho que mescla tanto os temas de estratégia quanto governança corporativa.

\section{Figura 13}

Frequência das palavras-chave

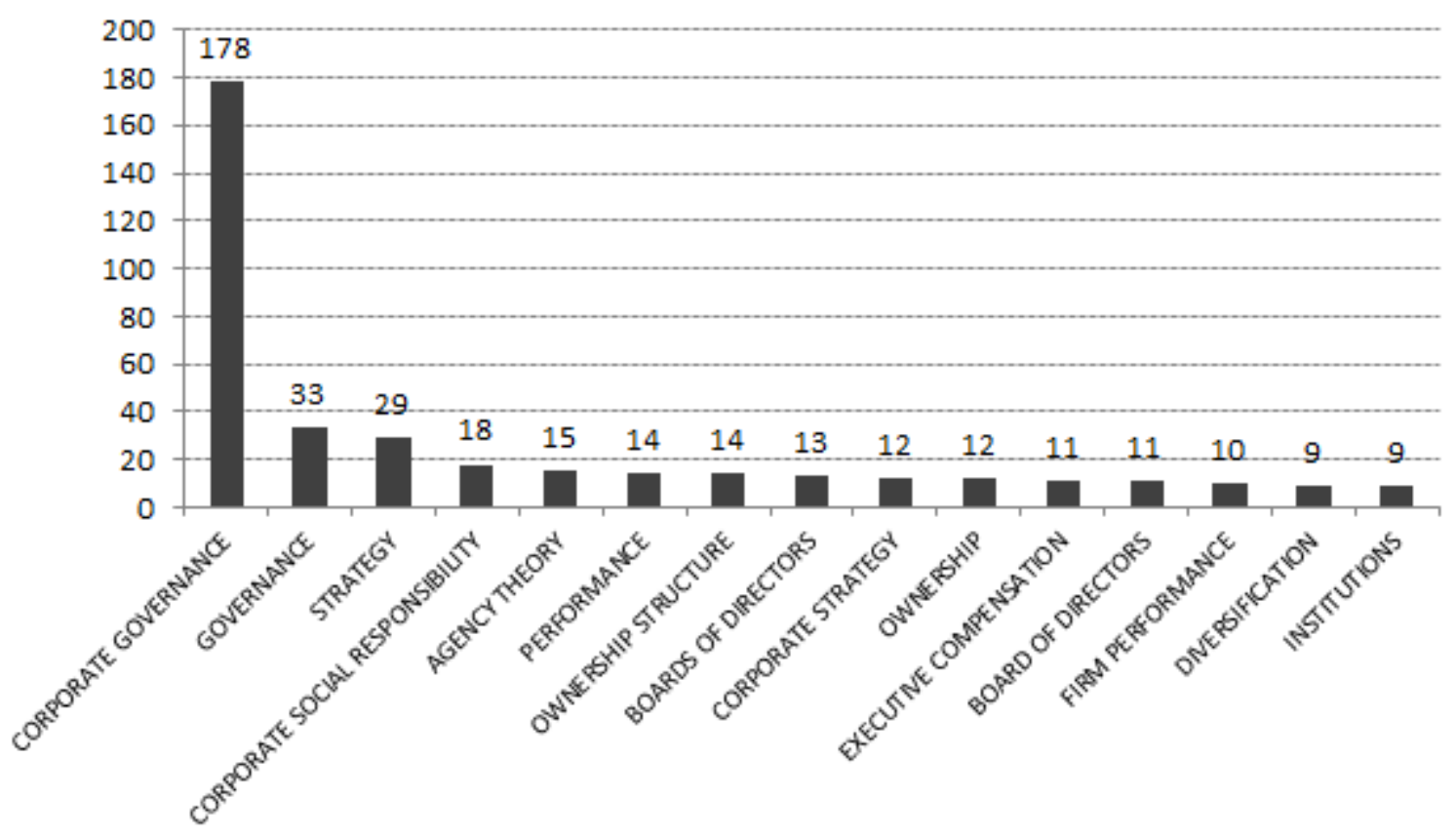

Fonte: Elaborado pelos autores. 
Figura 14 -

Diagrama de relacionamento de termos (mínimo 58 ocorrências)

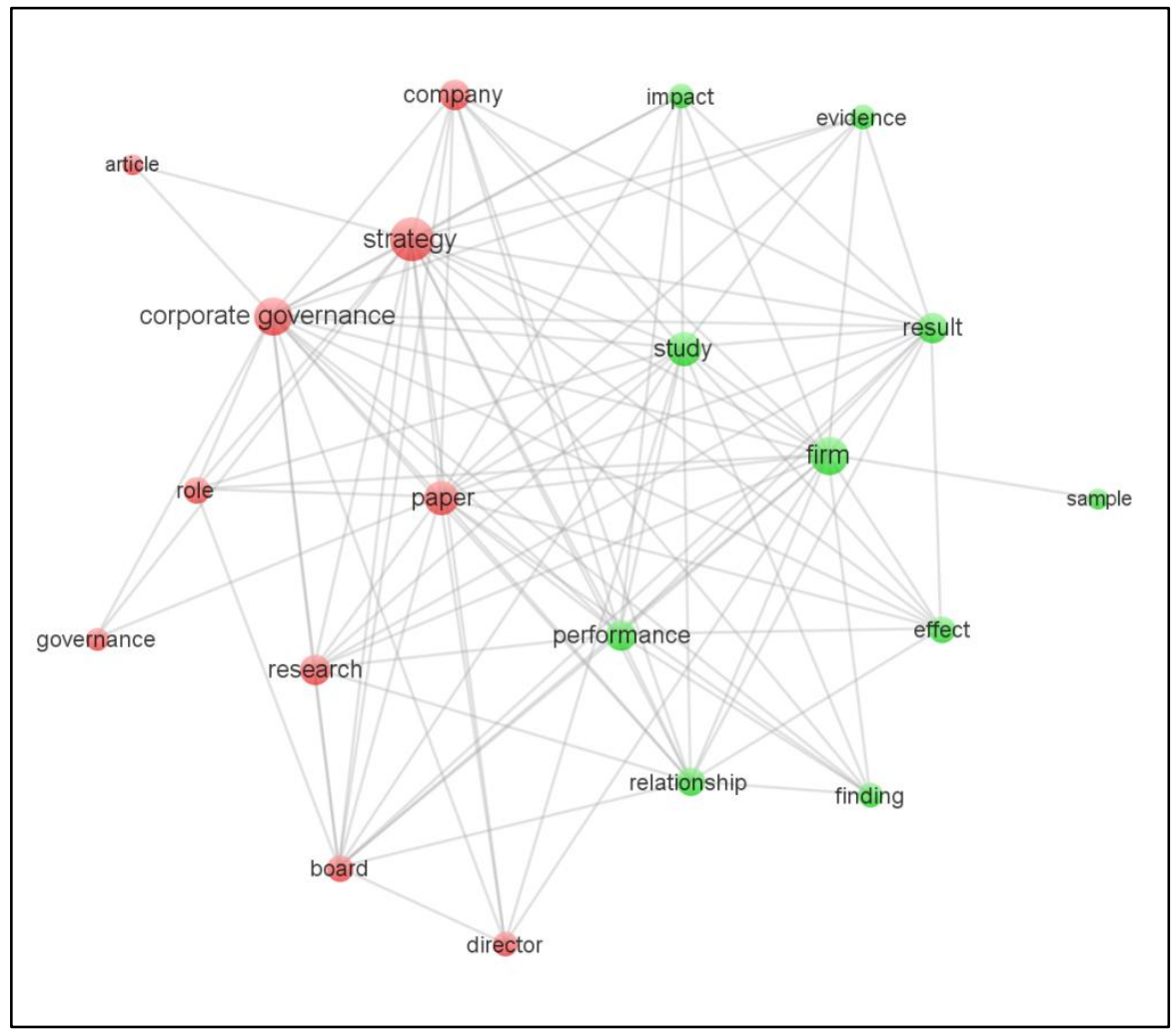

Fonte: Elaborado pelos autores.

\section{Considerações Finais}

Recuperando o objetivo deste trabalho, o presente artigo busacava realizar uma pesquisa bibliométrica introdutória para explorar o campo de pesquisa da Governança Corporativa e de sua relação com a Estratégia Empresarial, avaliando aspectos como principais trabalhos, autores, local de publicação, temas e palavraschave de pesquisa. A base de dados Web of Science da Thomson Reuters foi utilizada, em conjunto com o software VOSViewer.

Um dos primeiros achados do trabalho seria que a partir da década de 2000 começa a ocorrer na literatura uma maior interação entre Governança Corporativa e Estratégia - fato de alguma forma resultante do aumento de publicações a partir da segunda metade da década de 2000 e do aumento do número de citações a partir da primeira metade da mesma década. Essa afirmação somente deve ser colocada em perspectiva pelo próprio comentário de Neely (2005), mas também pelo que ficou 
posteriormente evidenciado que os trabalhos em Governança Corporativa derivam em grande parte de trabalhos seminais na área de Teoria da Agência (com Jensen e Fama como principais autores). Esse ponto é também suportado pela análise de cocitação dos próprios autores, que dão grande expressão aos nodos de Jensen e Fama e também pelo agrupamento bibliográfico dos textos, que destaca o trabalho de 1983 de Fama e o de 1976 de Jensen.

Um segundo ponto é que a conexão entre Governança Corporativa e Estratégia traz também uma série de temas "satélites", como ficou ilustrado no caso dos principais trabalhos citados e análise de palavras-chave. A questão de Geração de Valor ao Acionista é relevante, pois acaba sendo um dos lemas do próprio processo de Financeirização. Além disso, temas relacionados como venture capital, instituições, diversificação, etc. também estão presentes.

O terceiro achado proposto se refere à autoria dos trabalhos sobre o tema. Em alguma medida pode-se dizer que a produção científica é dispersa, dado que os nove principais autores são responsáveis apenas por pouco mais de $10 \%$ dos artigos da amostra. Neste caso também vale um aparte acerca dos trabalhos iniciais em Custos de Agência e Teoria da Firma, pois embora não apareçam entre os mais profícuos, novamente os economistas Fama e Jensen são bastante relevantes em termos de representatividade da produção, medida por meio das cocitações. Outros trabalhos relevantes de instituições e governança, como os de Olivier Williamson também são citados, corroborando que a área parece se utilizar bastante das referências clássicas.

O quarto ponto se refere ao local dessa produção científica. Mesmo sendo os Estados Unidos o país com maior número de publicações, a Inglaterra apresenta produção bastante relevante. Mais do que isso, os diagramas obtidos sugerem grande intercâmbio entre os trabalhos de todos os países, não havendo isolamento ou regionalização (em seu sentido negativo) na pesquisa.

O quinto ponto se refere aos periódicos nos quais tal pesquisa tem sido publicada. Por um lado, como seria de se esperar, estão os periódicos típicos de Estratégia e Gestão Empresarial. Por outro, pôde ser identificado também periódicos da área de Economia, sobretudo aqueles relacionados ao embasamento teórico da Governança Corporativa (nova economia institucional, teoria da firma, etc.), e também da área de Contabilidade e Finanças, abordando principalmente a 
governança corporativa no sentido de dar transparência para as informações financeiras divulgadas ao mercado de capitais.

Por fim, vale um comentário acerca da própria relevância de estudos bibliométricos como este. Por fim, como comenta Mugnaini (2006), a importância de estudos bibliométricos deriva da necessidade de avaliar a produtividade e a qualidade da pesquisa dos diversos atores acadêmicos, detectando modelos e padrões de comportamento em sua produção científica. Justamente por isso, a relevância dos estudos bibliométricos reside em caracterizações que privilegiam a abrangência com algum detrimento da profundidade, criando grandes panoramas de pesquisa que permitem o posterior trabalho enfocado nas diversas lacunas e oportunidades de pesquisa identificadas por tais estudos.

Assim como qualquer trabalho de revisão bibliométrica, principalmente aqueles que se ocupam de fazer um mapeamento geral de área de pesquisa, este deve ser tomado com plena ciência de suas limitações: restrição da base de pesquisa escolhida, que não representa toda a produção científica da área; possibilidades de erros na padronização dos campos (ex. autores, periódicos etc.) o que pode levar a conclusões parcialmente incorretas; e o próprio caráter generalista do trabalho que, em virtude de sua escolha e recorte de pesquisa, é conduzido em detrimento do trabalho com questões mais aprofundadas.

\section{Referências}

ANDRADE, A.; ROSSETTI, J. P. Governança corporativa: fundamentos, desenvolvimento e tendências. In: Governança corporativa: fundamentos, desenvolvimento e tendências. Atlas, 2004.

EISENHARDT, K. M. Making fast strategic decisions in high velocity environments. Academy of Management Journal, v. 32, 1989.

CAPRON, M., CHIAPELLO, E., COLASSE, B., MANGENOT, M.; RICHARD, J.. Les normes comptables internationales, instruments du capitalisme financier. La Découverte, 2005.

DALLERY, T.. Post-Keynesian theories of the firm under financialization. Review of Radical Political Economics, v. 41, n. 4, p. 492-515, 2009.

DENIS, D. K. Twenty-five years of corporate governance research... and counting. Review of financial economics, v. 10, n. 3, p. 191-212, 2001.

DONADONE, J. C. ; GRÜN, R. ; DIAS, A. V. C. ; RACHID, A. ; ZILBOVICIUS, M. ; QUELHAS, O. L. G. ; GOHR, C. F. ; SANTOS, c. I. ; MUNDO NETO, M. ; CAAMANO, P. C. . As Novas formas de Atuação e Configuração da 
Engenharia de Produção. Tópicos Emergentes e Desafios Metodológicos em Engenharia de Produção: Casos, Experiências e Proposições. : , 2010

ERTURK, I., FROUD, J., JOHAL, S., LEAVER, A.; WILLIAMS, K. General introduction: Financialization, coupon pool and conjuncture. Financialisation at Work, p. 1-44, 2008.

FIGUEIREDO, L.M.. Distribuição da literatura Geológica Brasileira; estudo bibliométrico. Ciência da Informação, v. 2, n.1, p. 27-40,1973

FROUD. J; JOHAL, S.; LEAVER, A.; WILLIAMS, K. Financialization and Strategy: Narrative and Numbers. Routledge, 2006.

GILLAN, S. L. Recent developments in corporate governance: An overview. Journal of corporate finance, v. 12, n. 3, p. 381-402, 2006.

GUEDES, V. L. S.; BORSCHIVER, S. Bibliometria: Uma Ferramenta Estatística Para a Gestão da Informação e do Conhecimento, em Sistemas de Informação, de Comunicação e de Avaliação Científica e Tecnológica. Anais do VI CINFORM. Salvador. 2005.

GUTTMANN, R.. Uma introdução ao capitalismo dirigido pelas finanças.Novos estudos-CEBRAP, n. 82, p. 11-33, 2008.

HART, O. Corporate governance: some theory and implications. The economic journal, p. 678-689, 1995.

INSTITUTO BRASILEIRO DE GOVERNANÇA CORPORATIVA. Código das Melhores Práticas. Disponível em: < http://www.ibgc.org.br/inter.php?id=18180> Acesso em 28 de Março de 2015

JENSEN, M. Agency cost of free cash flow, corporate finance, and takeovers. Corporate Finance, and Takeovers. American Economic Review, v. 76, n. 2, 1986.

JENSEN, M. C. The modern industrial revolution, exit, and the failure of internal control systems. The Journal of Finance, v. 48, n. 3, p. 831-880, 1993.

JENSEN, M. ; MECKLING, W. Theory of the Firm: Managerial Behavior. Agency Costs and Ownership Structure. Journal of Financial Economics, v. 3, 1976.

JENSEN, M.; RUBACK, R. The market for corporate control: The scientific evidence. Journal of Financial economics, v. 11, n. 1, p. 5-50, 1983.

MAIA, E. L. Comportamento Bibliométrico da Língua Portuguesa. Ciência da Informação, Brasília, №. 2, p. 99-138, 1973.

MUGNANI, R. Caminhos para adequação da avaliação da produção científica brasileira: impacto nacional 2versus internacional [tese]. São Paulo: Universidade de São Paulo; 2006

NEELY, A. The Evolution of Performance Measurement Research. International Journal of Operations \& Production Management. v.25, n. 12, p. 1264-1277. 2005

OKIMURA, R. Estrutura de propriedade, governança corporativa, valor e desempenho das empresas no Brasil. 2003. Dissertação de Mestrado em Administração. Faculdade de Economia, Administração e Contabilidade, Universidade de São Paulo, São Paulo, 2003.

PERROW, C. Economic Theories of Organization. In: ZUCKIN, S.; DIMAGGIO, P. Structures of Capital, Cambridge University Press, 1986

RAJAN, R. G.; ZINGALES, L. Power in a Theory of the Firm. National Bureau of Economic Research, 1997.

SHLEIFER, A.; VISHNY, R. W. A survey of corporate governance. The journal of finance, v. 52, n. 2, p. 737-783, 1997.

STOCKHAMMER, E. Accumulation and European unemployment. 2000. 
STOCKHAMMER, E. Stock markets, shareholder value and investment. Focus on Austria, v. 1, p. 95-110, 2003.

VANTI, N. Da Bibliometria à Webometria: uma Exploração Conceitual dos Mecanismos Utilizados para Medir o Registro da Informação e a Difusão do Conhecimento. Ciência da Informação. v. 31, n. 2, p. 152-162, 2002. 